8-17-2020

\title{
Maintaining Clinical Continuity Through Virtual Simulation During the COVID-19 Pandemic
}

Christa Esposito

Kelly Sullivan

Follow this and additional works at: https://digitalcommons.fairfield.edu/nursing-facultypubs Copyright 2020 SLACK Incorporated. All rights reserved.

The post-print has been archived here with permission from the copyright holder.

\section{Peer Reviewed}

\section{Published Citation}

Esposito, Christa Palancia, and Kelly Sullivan. "Maintaining Clinical Continuity Through Virtual Simulation During the COVID-19 Pandemic." The Journal of Nursing Education 59, no. 9 (2020): 522-25. https://doi.org/10.3928/ 01484834-20200817-09.

This item has been accepted for inclusion in DigitalCommons@Fairfield by an authorized administrator of DigitalCommons@Fairfield. It is brought to you by DigitalCommons@Fairfield with permission from the rightsholder(s) and is protected by copyright and/or related rights. You are free to use this item in any way that is permitted by the copyright and related rights legislation that applies to your use. For other uses, you need to obtain permission from the rights-holder(s) directly, unless additional rights are indicated by a Creative Commons license in the record and/or on the work itself. For more information, please contact digitalcommons@fairfield.edu. 
CLINICAL CONTINUITY DURING COVID-19

\section{Maintaining Clinical Continuity Through Virtual Simulation \\ During The COVID-19 Pandemic}

$\mathrm{X}$

$\mathrm{X}$ 


\begin{abstract}
Background

Amidst the COVID-19 pandemic, university instruction was transitioned online, including an undergraduate nursing clinical course. Charged with developing and executing virtual simulations, an online clinical course was conceived.

Methods

Simulated clinical experiences were crafted using a combination of student pre-assignments and video-conferencing facilitated by faculty. Each experience included the collective review of a case study and student-developed care plans before viewing and debriefing a series of videos. Students summarized their experience in a weekly written reflection.

Results

Student feedback was examined through their reflections and verbal responses. The videos served as catalysts for robust discussion. Overwhelmingly positive feedback related to an interactive experience, a heightened sense of teamwork, and enhanced comprehension by sharing differing perspectives of common experiences.

Conclusion

This educational innovation was successful in creating an engaging environment that facilitated student learning and a sense of togetherness during a global pandemic. The use of technology enabled the continuity of a productive teaching-learning experience.
\end{abstract}

Keywords: online learning, nursing education, interactive video communication, COVID19, pandemic, technology, virtual simulation, virtual teaching 


\section{Maintaining Clinical Continuity Through Virtual Simulation During The COVID-19 Pandemic}

Traditionally, undergraduate nursing education has been campus-based, mainly due to the introduction of, and need for, the assessment of psychomotor nursing skills. Students have assimilated these skills with sustained experiences in clinical practica, caring for patients in various outpatient and inpatient settings. However, over the past decade, nursing education has been transforming through technology, simulation, and online learning. Student acceptance and adoption of technology has eased this transition to distance teaching and learning.

Halfway into the spring semester of 2020, the Novel Coronavirus SARS CoV-2 (COVID19) pandemic demanded that university instruction be transitioned fully online. Charged with developing and executing an online undergraduate maternal-child nursing clinical course, a virtual teaching-learning experience was conceived. While simulation in nursing education is a proven pedagogy, virtual simulation conducted solely online is a new opportunity created out of the COVID-19 pandemic quarantine (Hayden et al., 2014). Technology, faculty collaboration, and student engagement provide the framework for this virtual clinical course. The purpose of sharing this educational innovation is to disseminate the modern methods for clinical teachinglearning and the positive outcomes of a novel pedagogy during extraordinary pandemic conditions.

\section{Methods}

\section{Continuity Needs Assessment}

The first step to establishing the virtual continuity of the clinical course, was to conduct a student and faculty needs assessment (via email) to ascertain whether they had the necessary hardware, WiFi, and private space needed for virtual teaching-learning. The university provided web-based educational and video-conferencing platforms for student and faculty communication. 


\section{CLINICAL CONTINUITY DURING COVID-19}

Seventeen, second-semester, third-year traditional undergraduate students, divided in three groups, were enrolled in the clinical simulation. No student concerns were identified in the needs assessment. Faculty in need of hardware and/or training on the online platforms were assisted by the course coordinator and university IT department. Ongoing technological support was provided for students and faculty by the university's IT department with video tutorials, email, and help-desk hotline.

\section{Creation of Clinical SIMs}

The second step in establishing clinical continuity was the creation of the virtual clinical simulation experiences (SIMs). The course coordinator met via video-conferencing with the clinical faculty to encourage input and feedback on the development of the SIMs. Online teaching best practices were examined and reviewed with the faculty to systematize the SIMs. Faculty engagement of the students via live video-conferencing was compulsory. Faculty was expected to provide timely feedback to student requests, emails, and assignments to ensure that students felt embraced and present within the virtual world (Seckman, 2018). Fortunately, prior to the interruption of the COVID-19 quarantine, each clinical group had met for one, on-campus SIM in the university's SIM lab. That SIM day was a comprehensive overview of maternal-child nursing with hands-on practice of postpartum maternal and newborn manikin exams and participation in a high-fidelity simulated vaginal birth. To segue online, five standardized six-hour virtual SIMs were crafted around the existing course objectives using a combination of asynchronous, independent student pre-assignments and synchronous videoconferencing with clinical faculty. The pre-assignments included a case study and care plan development on the SIM topics including (a) spontaneous vaginal birth, (b) postpartum hemorrhage, (c) perinatal palliative care, (d) newborn assessment and care, and (e) preeclampsia. 


\section{CLINICAL CONTINUITY DURING COVID-19}

The pre-assignments accounted for one to two hours of the SIM depending on the content and number of videos presented, which also informed the amount of debriefing time. After each SIM, students were required to write a reflection of the SIM experience, for which one hour was credited. Table 1 provides the timeline for one of the simulated experiences, perinatal palliative care.

Table 1.

Timeline for Virtual Clinical Simulation

\begin{tabular}{|c|c|c|c|}
\hline SIM Topic & Pre-Assignment & Videos /Debriefing & Assessment \\
\hline $\begin{array}{l}\text { Perinatal } \\
\text { Palliative Care }\end{array}$ & $\begin{array}{l}\text { 1. Case study (1 hour): } \\
\text { Independently, thoroughly } \\
\text { review the perinatal palliative } \\
\text { care case study, define any new } \\
\text { terms and conditions for your } \\
\text { comprehension. } \\
\text { 2. Create a "mini-care plan." } \\
\quad \text { (1 hour) } \\
\text { Mini-care plan template: } \\
\text { S: } \\
\text { O: } \\
\text { A: Two NANDA diagnoses } \\
\text { P: Interventions with rationale }\end{array}$ & $\begin{array}{l}\text { 1. Debrief case study } \\
\text { (1.5 hours): } \\
\text { Meet via video- } \\
\text { conferencing with } \\
\text { clinical faculty to } \\
\text { explore knowledge and } \\
\text { feelings about the case } \\
\text { study. } \\
\text { a. Summarize the } \\
\text { case study and } \\
\text { share care plans. } \\
\text { b. Review the } \\
\text { priorities of this } \\
\text { case. } \\
\text { 2. Pre-brief SIM } \\
\text { video. } \\
\text { (15 minutes) } \\
\text { 3. Watch SIM video } \\
\text { on perinatal } \\
\text { palliative care. } \\
\text { (15 minutes) } \\
\text { 4. Debrief video. } \\
\text { (1 hour) }\end{array}$ & $\begin{array}{l}\text { Reflection Paper } \\
\text { ( } 1 \text { hour): } \\
\text { Write a } \\
\text { reflection of one- } \\
\text { two pages on the } \\
\text { virtual SIM. }\end{array}$ \\
\hline
\end{tabular}

\section{Dissemination and Execution}




\section{CLINICAL CONTINUITY DURING COVID-19}

The third step in establishing clinical continuity was the dissemination of the weekly SIM plans to students and faculty through the university's online educational platform. Clear expectations, objectives, and instructions were outlined in these weekly continuity plans (Huun, 2018). The case studies and hyperlinks to videos were provided via a web-based platform to make the materials easily accessible (Decelle, 2016). The virtual SIMs were executed by the clinical faculty, on the originally scheduled clinical day, through video-conferencing. Faculty and students collectively reviewed the case study and their individual care plans before viewing and immediately debriefing a series of videos. When available, SIM videos previously produced by the university were used along with compatible publicly available videos. The videos were catalysts for robust discussion specific to each topic on nursing care, clinical management, critical thinking, and integration of theory into clinical practice. Lastly, all 17 students submitted a weekly, written, one to two-page reflection on each virtual SIM.

\section{Results}

We examined the students' feedback of the virtual SIMs revealed in their required written reflections and verbal responses during the video-conferencing. We found that the virtual SIMs garnered overwhelmingly positive feedback from $100 \%$ of the students related to the students': (a) comprehension of the material, (b) appreciation of teamwork with their peers, and (c) a much needed sense of community during the COVID-19 quarantine. Many students mentioned their unexpected satisfaction with, and enriched learning, through the virtual SIMs.

Feedback was sought from the clinical faculty executing the SIMs. One of the three faculty shared their thoughts, which were congruent with the student perceptions and themes. The faculty were challenged with this sudden and urgent change in their teaching role requiring the adoption of a novel teaching pedagogy and the use of new technology simultaneous with the 


\section{CLINICAL CONTINUITY DURING COVID-19}

disruption in their personal lives and independent clinical nursing employment. The faculty rose to this challenge providing a student-centered, industrious, and highly successful virtual clinical experience.

\section{Deep Comprehension}

The SIMs were described as valuable in exposing the students to scenarios that they may not have seen in a physical clinical setting. The SIMs allowed more time for the in-depth discovery of each clinical scenario likely not presented in an on-site clinical experience, which enhanced the students' comprehension of these concepts. For example, as part of the vaginal birth SIM, home birth and water birth videos were analyzed for nursing care in these unique settings. This speaks to the relevance of this SIM when, amidst the COVID-19 crisis, the public's desire for out-of-hospital birth increased substantially (de Freytas-Tamura, 2020). Students suggested that the sharing of their individual care plans and varying nursing diagnoses created different viewpoints in a way that they had not appreciated in other on-site clinical experiences. A common theme in student reflections was their surprise at the growth in knowledge of content, already covered in their didactic course, made more tangible under the guidance of the faculty.

\section{Teamwork and Collaboration}

Students shared that they felt a culture of collaboration and teamwork as they analyzed common case studies and content videos. Discussion led to the sharing of different ideas and perspectives related to the same clinical situation, which reportedly increased student learning. They felt that even though they did not experience the scenarios together, in-person, they were able to more intimately share their feelings. The newborn SIM was often mentioned in this regard. A case study on neonatal abstinence syndrome (NAS) followed by a video depiction of a 


\section{CLINICAL CONTINUITY DURING COVID-19}

young mother coping with her addiction and her newborn created great dialogue and critical thinking. Experiencing the mother's backstory, addiction through pregnancy, and virtually witnessing the neonatal outcome, made a profound impression on most of the students. The impact of visualizing the symptomatology and appropriate nursing care of a baby with NAS enriched their integration of theoretical knowledge into clinical practice. The students shared that each of them clung to a different aspect of the case study and video amplifying the overall analysis of the SIM.

\section{Sense of Community}

An unanticipated outcome of the virtual SIMs was a perceived sense of togetherness and community among the students. Students reflected that the SIMs fostered connectedness while the COVID-19 quarantine cultivated isolation. Reactions centered on the favorability of the scheduled, synchronous, live video-conferencing meetings directed by the faculty. Synchronous meetings gave students an appreciation of routine in light of the quarantine time warp and in comparison to other courses that were asynchronous or recorded. Reflections credited the faculty involvement in providing rich conversation and student engagement in responsive discussion. Connecting virtually with their clinical team became a welcomed bonus to their clinical learning, creating a community bond in this uncertain, unprecedented time.

\section{Capacity for Improvement}

Student feedback of the virtual SIMs was solicited throughout the five weeks by the course coordinator. Although the student feedback was affirmative overall, all of the students commented on their disappointment over the lack of an in-hospital experience. Four students requested a one day, in-hospital opportunity, when they return next semester. Three students mentioned that the number of videos in one SIM created fatigue and suggested routinely 


\section{CLINICAL CONTINUITY DURING COVID-19}

debriefing after each video; this is best practice and encouraged of clinical faculty. Two students voiced the preference of a traditional written case study pre-assignment over a video-story due to the ease it provided in creating their care plan. Lastly, two students verbalized frustration with the inability to have conversations with patients, particularly regarding patient education. Future virtual SIMs can include standardized patients to play the role of an antepartum woman and new mom. These student insights will inform future virtually simulated clinical experiences to enhance student proclivity.

\section{Conclusion}

Necessity is the mother of invention, a pandemic demands innovation. Despite the lack of time for intensive faculty training of online teaching pedagogy, this educational innovation was effective in achieving the clinical course objectives and facilitating student learning. Initiating a judicious needs assessment of faculty and students secured the foundation for a successful transition online. Faculty were coached vis-à-vis online best practices and received ongoing support of the course coordinator and the IT department. The need for timely faculty training and technology support are paramount (Howe et al., 2018; Richter \& Schuessler, 2019). The innovation of this novel virtual clinical course was fostered by the faculty collaboration and acceptance of the time constraint imposed by the unique and unavoidable conditions of the COVID-19 pandemic. Faculty served as guides to engage the students in active learning with clearly-defined synchronous and asynchronous assessments (Decelle, 2016 \& Sinacori, 2020).

In spite of the unfulfilled expectations for an on-site, inpatient clinical rotation, student feedback elucidated a tremendously positive virtual SIM experience. A source of student satisfaction was the importance of using live video-conferencing to create presence and unity among the group, which enhanced learning. Faculty encouraged the students to allow for the 


\section{CLINICAL CONTINUITY DURING COVID-19}

visualization of their clinical team to increase engagement and further student interaction. This echoes the work of Seckman (2018) encouraging the use of live video visualization of adult learners to capture an active learning experience. Congruent with past research, there was agreement amongst the faculty and students that the use of videos, debriefing, and faculty interaction created a sense of community (Stanley et al., 2018 \& Yeun et al., 2020).

The landmark study by Hayden et al. (2014) validated that $50 \%$ of nursing education garnered through simulation yielded clinical proficiency in the academic setting, as well as at six-weeks, three-months, and six-months post-graduation. This type of SIM was conducted inperson or in an on-campus SIM lab. While there is a gap in the literature on virtual simulation and nurse proficiency, in a small randomized controlled trial, Padilha et al. (2019) found that virtual SIM increased knowledge and learner satisfaction in nursing students in Portugal. Future large scale research on virtual simulation is needed to track proficiency, knowledge, and satisfaction of student nurses.

Ultimately, the goal is to craft virtual simulations with an emphasis on student engagement and learning (Shin et al., 2019). This educational innovation was effective in creating an environment that facilitated student learning, satisfaction, and a sense of togetherness during the COVID-19 pandemic. With the explosion of telehealth services during the COVID19 quarantine, technology has solidified its place in our healthcare system (Terry, 2020). Consistent with the affirmative outcome of our virtual SIM, nurse-educators have an opportunity to mentor student nurses in an evolving future in healthcare with the use of technology and diverse resources. (Huun, 2018). Additional training on this pedagogy can prepare nurseeducators to meet the needs of the current environment. The use of an innovative online teaching 


\section{CLINICAL CONTINUITY DURING COVID-19}

pedagogy can enable a productive teaching-learning experience; research is warranted to determine students' clinical proficiency. 


\section{References}

Decelle, G. (2016). Andragogy: A fundamental principle of online education for nursing. Journal of Best Practices in Healthcare Professional Diversity: Education, Research \& Policy, 9(2), 1263-1273. Retrieved from http://libdb.fairfield.edu/login?url=https://search.ebscohost.com/login.aspx?direct=true\& $\underline{\mathrm{db}=\mathrm{rzh} \& \mathrm{AN}=121668960 \& \text { site }=\text { ehost-live \&scope }=\text { site }}$

de Freytas-Tamura, K. (April 24, 2020). Pregnant and scared of 'covid hospitals,' they're giving birth at home. The New York Times. https://www.nytimes.com/2020/04/21/nyregion/coronavirus-home-births.html

Hayden, J., Smiley, R.S, Alexander, M., Kardong-Edgren, S., Jeffries, P.R. (2014). Use of simulation in nursing education: National survey results. Journal of Nursing Regulation, 1(3), 52 -57. https://www.ncsbn.org/JNR_Simulation_Supplement.pdfDOIcli

Howe, D. L., Hsiu-Chin Chen, Heitner, K. L., \& Morgan, S. A. (2018). Differences in nursing faculty satisfaction teaching online: A comparative descriptive study. The Journal of Nursing Education, 57(9), 536-543. doi:10.3928/01484834-20180815-05

Huun, K. (2018). Virtual simulations in online nursing education: Align with quality matters. Clinical Simulation in Nursing, 22(1), 26-31. doi:https://doiorg.libdb.fairfield.edu:8443/10.1016/j.ecns.2018.07.002

Padilha, J.M., Machado, P.P., Ribeiro, A., Ramos, J., \& Costa, P. (2019). Clinical virtual simulation in nursing education: Randomized controlled trial. Journal of Medical Internet Research, 21(3):e11529. DOI: $\underline{10.2196 / 11529}$ 


\section{CLINICAL CONTINUITY DURING COVID-19}

Richter, S. L., \& Schuessler, J. B. (2019). Nursing faculty experiences and perceptions of online teaching: A descriptive summary. Teaching and Learning in Nursing, 14(1), 26-29. doi:10.1016/j.teln.2018.09.004

Seckman, C. (2018). Impact of interactive video communication versus text-based feedback on teaching, social, and cognitive presence in online learning communities. Nurse Educator, 43(1), 18-22. doi:10.1097/NNE.0000000000000448

Shin, H., Rim, D., Kim, H., Park, S., \& Shon, S. (2019). Educational characteristics of virtual simulation in nursing: An integrative review. Clinical Simulation in Nursing, 37(1), 1828. doi:https://doi-org.libdb.fairfield.edu:8443/10.1016/j.ecns.2019.08.002

Sinacori, B. C. (2020). How nurse educators perceive the transition from the traditional classroom to the online environment: A qualitative inquiry. Nursing Education Perspectives, 41(1), 16-19.. doi:10.1097/01.NEP.0000000000000490

Stanley, M. J., Serratos, J., Matthew, W., Fernandez, D., \& Dang, M. (2018). Integrating video simulation scenarios into online nursing instruction. The Journal of Nursing Education, 57(4), 245-249. doi:10.3928/01484834-20180322-11

Terry, K. (2020, March 4). Telehealth seen as a key tool to help fight COVID-19. Medscape Medical News. https://www.medscape.com/viewarticle/926269

Yeun, E. J., Chon, M. Y., \& An, J. H. (2020). Perceptions of video-facilitated debriefing in simulation education among nursing students: Findings from a Q-Methodology study. Journal of Professional Nursing, 36(2), 62-69. doi:https://doiorg.libdb.fairfield.edu:8443/10.1016/j.profnurs.2019.08.009 